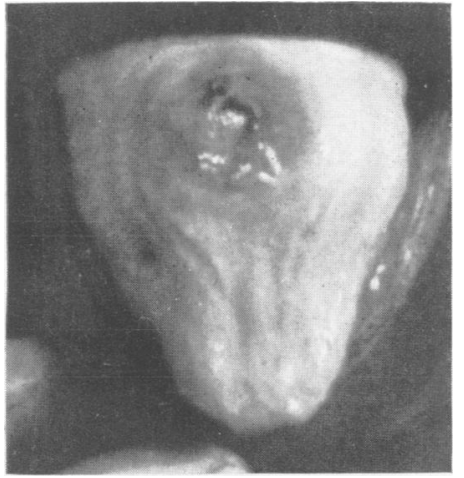

Fig. 1.-Sore on tongue, case 1.

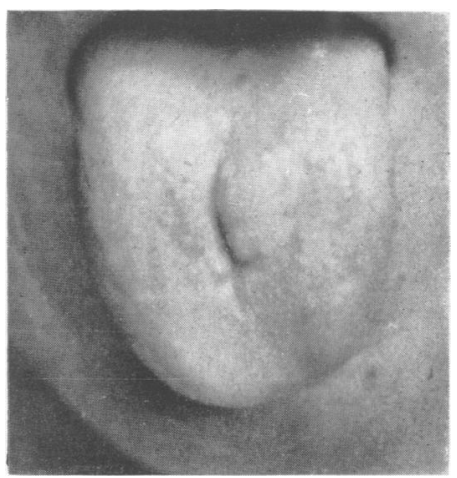

FIG. 2.-Fissured ulcer on tongue, case 2.

\title{
CORRESPONDENCE
}

Letters are welcome on all matters of general interest. Publication does not necessarily imply that the Editor agrees with the views expressed.

\section{A SPECIAL QUALIFICATION IN} VENEREOLOGY

Sir,-Advertisements in the medical press for medical officers for venereal disease clinics reveal marked differences in the professional qualifications required. For example, one recent advertisement stipulated an M.R.C.P. or F.R.C.S. as essential, while in other cases a " higher medical qualification" has been required, or it has been indicated that the "possession of a D.P.H. or other additional qualification would be an advantage."

These varying requirements reflect the views of employing authorities-whether voluntary hospital or health department.

The statutory requirements for a venereal disease medical officer, as laid down in the Local Government (Qualifications of Medical Officers and Health Visitors) Regulations 1930, are not expressly demanded in all cases as a necessary prerequisite to appointment. Indeed, it is by no means unknown for a medical officer to whom the conduct of a venereal disease clinic has been entrusted to attend the nearest large centre and obtain this qualification while actually conducting his own clinics.

Higher qualifications are proof of postgraduate study but, except in those in which venereal diseases may be professed as the major subject, do not necessarily imply any deep knowledge of venereology. The present-day C.P.H. and D.P.H. courses do not make any detailed study of this subject.
The statutory requirements referred to above can at most mean a reasonable primary training for the rare enthusiasts who can learn enough to make their own future experience. The majority, however, request the certificate as an additional lever for public health appointments, after expiation of the 130 hours, without having made any serious attempt to acquire reasonable basic knowledge.

In the case of Service specialists a very wide experience of recent infections may be obtained, but they do not have to deal with many of the manifestations and problems commonly encountered in civilian clinics.

The absence in venereology of any recognized postgraduate qualification comparable to those available in other specialities, and the low official standards, have contributed to the belief that venereology is not a speciality. It is regarded as an unimportant side-line, and often made the stipendary prerogative of the junior surgeon, physician, etc., or allocated to the junior assistant medical officer of health.

This position, which would not be tolerated in other departments, has been permitted to obtain too long by venereologists who have not sufficiently emphasized the scope and importance of their speciality and insisted upon adequate training and status before responsibility is taken.

It is the duty of venereologists to secure for the medical services of the country competently trained persons to carry out this work in the best interests of the community. It is conceded that 
in many venereal disease departments a consistently high standard is maintained, but in others this has not yet been achieved. The isolated lot of the part-time one-man clinic is admittedly difficult; there is often no possibility of easy consultation over clinical or sociological problems. Attendance at meetings of the Medical Society for the Study of Venereal Diseases is often impossible because of clinic times, or is not encouraged by the employing authority and, at best, is left as a non-official expense and enthusiasm. It is hoped that under the new Health Service these matters may be remedied.

The lack of a special diploma or other instrument indicating a specialist status in venereology has contributed materially to the present unhappy position. That the number of venereologists is relatively small, if we consider only those whose primary appointments lie in this field, must no longer be the excuse for apathy.

What are the possible courses of remedial action? These are : (a) the institution of a diploma in venereology to be granted by an established examining body; (b) the creation of two classes of membership of the Medical Society for the Study of Venereal Diseases (possible alteration of its title to Association/Society of Venereologists and M.S.S.V.D.), namely, a junior associatemembership equivalent to the present membership, and a senior Diplomate Fellowship, by examination; or (c) the formation of a Faculty of Venereologists outside the structure of, but of necessity integrated with the M.S.S.V.D., the diploma of Fellowship of which would indicate approbation as a specialist.

An additional cogent reason advanced by $\mathrm{Mr}$. A. J. King (personal communication) is the desire of " the constant stream of overseas postgraduates who always enquire about the possibility of a specialist's qualification in these subjects. Naturally they wish to achieve such a qualification as evidence of the good work they have done over here."
The standard of professional attainment envisaged would be equal for the diploma or for either fellowship. The first course offers certain obvious advantages - a diploma obtained by examination, conducted by an established examining body with the prestige of its long traditions, would more immediately be recognized and accepted as indubitable evidence of professional attainment in venereology by those authorities seeking to fill appointments.

Either of the other courses of action might in practice be easier to institute, but the principal disadvantage is that, while the professional standard exacted would be equally high, there would undoubtedly be a greater time lag before the value of the qualification was accorded full recognition.

That there is a multiplicity of special diplomas only indicates that other specialities have realized their value in securing and maintaining high standards.

The Medical Society for the Study of Venereal Diseases has long existed to encourage the " study" of the venereal diseases: it is not too much to expect this, the proper, and in fact the only, body representative of venereologists in this country to concern itself actively with the formulation of some generally accepted standard of proficiency in this work. - The demand for a special ad hoc postgraduate qualification in venereology by the members of this society would give their council a mandate for urgent action.

To those already established and recognized, such a diploma can only mean "an additional qualification," : to future aspirants in venereology it will be the hall mark of specialization.

We are, etc.,

\section{A. E. W. McLACHLAN DONALD D. BROWN}

Bristol, July 1947.

\section{BOOK REVIEWS}

\author{
TREPONEMATOSIS \\ By Ellis H. Hudson; \\ edited by Henry A. Christian \\ (Oxford Medical Publications. 1947. Pp. 122.) \\ Price 12s. 6d. net.) \\ In the year 1493 a small band of men returned \\ in triumph to Spain and reported the presence of \\ new lands in the West; they brought with them \\ new maps and charts, botanical and geological \\ specimens, and a few captured Indians to show at \\ the court of Ferdinand and Isabella. Whether or \\ not they brought with them at the same time a new \\ and fell disease which, in the course of a few years, \\ was to spread to all Europe and far to the East, is
}

a problem which has now interested medical historians for hundreds of years.

The argument as to the responsibility of Columbus in introducing the disease to Europe is as old as the name syphilis itself; and each of the various, never conclusive, arguments advanced by the protagonists on both sides have been repeated and elaborated through the centuries. The more vocal opposers of the Columbian theory, not surprisingly perhaps from across the Atlantic, have pointed to the existence of yaws in the African native and, in drawing attention to its spread to the West, have tried to show, by attempting to prove that yaws and syphilis were the same disease, that the boot was, indeed, on the other foot. 